\title{
Media Informasi Website pada Wisata Kuliner Panganan Khas Mandar
}

\author{
Dian Megah Sari ${ }^{1}$, Asmawati S. ${ }^{2}$ \\ ${ }^{1,2}$ Fakultas Teknik, Universitas Sulawesi Barat, Jln. Prof. Dr. Baharuddin Lopa, Majene, 9412 \\ e-mail: 1dianmegahsari@unsulbar.ac.id,e-mail: ${ }^{2}$ asmawati.s@ unsulbar.ac.id
}

Submitted Date: August $11^{\text {th }}, 2020$

Revised Date: September $25^{\text {th }}, 2020$
Reviewed Date: September $21^{\text {st }}, 2020$

Accepted Date: September $30^{\text {th }}, 2020$

\begin{abstract}
Limited information on typical Mandar culinary in Majene Regency, such as types of food, location of food, operating hours, and transportation are references to provide complete information to tourists. Information about typical Mandar food requires the role of technology in it, considering that it plays a very important role in helping tourists or local people to find information about Mandar specialties, it is requires a media capable of providing information about the address of the place to eat, the type of food served, the hours of operation, and transportation used. The purpose of this research is to design website information media on Mandar culinery touris in Majene regency that can help tourist or local communities. Based on a series of research it can be conclude that the website information media on typical Mandar culinary tours in Majene Regency can make it easy for tourist or local people to get information about the Mandar culinary tours and decide which restaurant wiil they choice.
\end{abstract}

Keywords: Majene; Website information Media; Typical Mandar Food; Culinary Tours

\begin{abstract}
Abstrak
Terbatasnya informasi tentang kuliner panganan khas Mandar di Kabupaten Majene, seperti jenis panganan, lokasi panganan, jam operasi, dan transportasi menjadi referensi untuk memberikan informasi lengkap kepada wisatawan. Informasi tentang panganan khas Mandar membutuhkan peran teknologi di dalamya, mengingat hal tersebut berperan sangat penting untuk membantu wisatawan atau masyarakat lokal mencari informasi tentang panganan khas Mandar, maka diperlukan media yang mampu memberikan informasi tentang alamat tempat makan, jenis makanan yang disajikan, jam operasi, dan transportasi yang digunakan. Tujuan penelitian ini yaitu merancang media informasi website pada wisata kuliner panganan khas Mandar di Kabupaten Majene yang dapat membantu para wisatawan atau masyarakat lokal. Berdasarkan serangkaian tahapan penelitian yang dilakukan dapat disimpulkan bahwa media informasi website pada wisata kuliner panganan khas Mandar di Kabupaten Majene dapat memberikan kemudahan bagi para wisatawan atau masyarakat lokal dalam mendapatkan informasi terkait wisata kuliner panganan khas Mandar serta memutuskan restoran yang akan mereka pilih.
\end{abstract}

Kata Kunci: Majene; Media Informasi Website; Panganan Khas Mandar; Wisata Kuliner

\section{Pendahuluan}

Wisata kuliner terutama kuliner panganan khas Mandar sudah menjadi sebuah jenis wisata yang dampaknya sangat banyak bagi perkembangan daerah, dengan menyediakan panganan-panganan khas Mandar maka dapat menjadi salah satu nilai penting untuk mengembangkan potensi daerah. Untuk itu perlu dibuat sebuah media informasi untuk membantu para wisatawan maupun masyarakat lokal dalam menikmati atau mencari tahu tentang panganan khas Mandar di Kabupaten Majene.

Media informasi bagi wisatawan maupun masyarakat lokal saat ini sangat penting, karena merupakan salah satu sarana informasi bagi wisatawan maupun masyarakat lokal yang belum mengetahui ragam kuliner panganan khas Mandar di kabupaten Majene dan tempat-tempat yang menyediakan panganan khas tersebut. Dengan dibangunnya media informasi website ini, masyarakat diharapkan dapat menemukan destinasi 
panganan khas Mandar dan wisata kuliner yang belum dicoba oleh masyarakat lokal ataupun para wisatawan tanpa harus membuka satu persatu website di internet. karena itulah diperlukan adanya sebuah media informasi berbasis website yang diharapkan dapat menyelesaikan permasalahanpermasalahan tersebut.

Berdasarkan uraian permasalahan yang telah dipaparkan maka peneliti ingin merancang dan membangun sebuah aplikasi berbasis website yang menyediakan informasi untuk membantu masyarakat mennemukan rekomendasi terkait panganan khas Mandar di Kabupaten Majene.

Permasalahan tentang sarana informasi wisata kuliner ini mendorong peneliti untuk berusaha menemukan solusi dan menciptakan sebuah sistem informasi. adapun beberapa penelitian sebelumnya yang diteliti berjudul "Sistem Informasi Wisata Kuliner di Kota Medan Berbasis Web" didapatkan hasil bahwa Perancangan sistem informasi wisata kuliner tersebut dapat membantu pemasaran dan promosi yang merata serta dapat dijangkau tanpa dibatasi waktu dan ruang yang membantu pengusahapengusaha wisata kuliner untuk memperkenalkan usaha mereka, hasil lainnya yaitu dengan pembuatan dan perancangan yang menampilkan desain menarik dapat menarik perhatian pengunjung sehingga mendapat kepuasan untuk melakukan pencarian informasi yang telah disediakan oleh pengembang sistem informasi kuliner di kota Medan. Dari hasil tersebut dapat disimpulkan bahwa fungsi dari sistem informasi berbasis website pada wisata kuliner di kota Medan ini telah berjalan dengan baik sesuai pruntukkannya.

Penelitian sebelumnya dengan judul "Sistem Informasi Wisata Kuliner Berbasis Web Sebagai Media Promosi Kuliner Di Kota Malang" didapatkan hasil bahwa Penampilan informasi lokasi atau google maps pada halaman detail tempat makan dapat membantu pengguna dalam melihat detail lokasi tempat makan. Penambahan informasi contact person yang lebih detail, seperti akun whatsapp, telegram, line, dapat membantu pengunjung untuk menghubungi pemilik tempat makan. Dari hasil tersebut dapat disimpulkan bahwa fungsi dari sistem informasi tersebut telah berjalan dengan baik sesuai peruntukkannya.

Penelitian sebelumnya dengan judul "Aplikasi web promosi kuliner dan rumah makan online" didapatkan hasil bahwa rancangan sistem yang dibuat telah memberikan informasi terkait kuliner dan rumah makan, melalui sistem WM-
Online, promosi kuliner dan rumah makan menjadi lebih luas dan pengaksesan dilakukan secara gratis. Selanjutnya melalui sistem WM-Online, diharapkan dapat meningkatkan omset dan jumlah pengunjung pada rumah makan tersebut, sistem WM-Online telah dapat diakses dan digunakan dengan baik melalui sistem webbrowser. Dari hasil tersebut dapat disimpulkan bahwa fungsi dari sistem WM-Online tersebut telah berjalan dengan baik sesuai peruntukkannya.

Penelitian sebelumnya dengan judul "Perancangan Sistem Informasi Wisata Kuliner Berbasis Web Dengan Menggunakan Ajax dan Code Igniter" didapatkan hasil bahwa Implementasi ajax telah memudahkan interaksi antarpengguna, Implementasi codeigniter telah memudahkan dalam pengelolaan dan pembuatan web. Dari hasil tersebut dapat disimpulkan bahwa fungsi dari sistem berbasis website dengan code igniter dan ajax telah berjalan dengan baik sesuai pruntukkannya.

Penelitian sebelumnya dengan judul "Rancang Bangun Sistem Informasi Wisata Kuliner Di Kota" didapatkan hasil bahwa adanya sistem kuliner ini sangat bermanfaat dan memberi kemudahan kepada masyarakat untuk mencari informasi mengenai tempat-tempat makan dengan baik dan memberi kemudahan serta jalan bagi masyarakat jika ingin mempromosikan usaha kulinernya secara online. Website wisata kuliner ini juga memberikan tampilan yang baru dan mudah untuk diakses. Berdasarkan hasil pengujian black box, aplikasi ini telah berjalan dan bekerja dengan baik dan berdasarkan hasil pengujian kuisioner, website wisata kuliner ini mendapat tanggapan yang positif dari pengguna dalam hal ini masyarakat umum yang dapat diamati dari hasil pengujian kuisioner di mana rata-rata nilai baik dari segi antarmuka maupun fungsinya sudah sangat menarik dan sangat mudah dioperasikan.

\section{Landasan Teori}

\subsection{Media Informasi}

Media informasi berkembang dengan pesatnya dan menjadi suatu media yang sangat diperlukan setiap saat, karena dengan memanfaatkan media informasi manusia bisa mendapatkan informasi yang akurat dan dapat mengikuti perkembangan teknologi saat ini, selain itu manusia juga bisa saling berinteraksi dan saling menyapa satu sama lain. Media informasi juga dapat memberikan kemudahan saat megirimkan pesan, di mana pesan bisa tersampaikan dengan mudah apabila media yang digunakan tepat sasaran 
maka informasi yang disampaikan bisa sangat bermanfaat bagi pembuat informasi dan penerima informasi

\subsection{Wisata Kuliner dan Panganan khas}

Wisata kuliner merupakan sebuah kata yang berasal dari bahasa voyages culinaires (Prancis) atau culinary travel (Inggris) yaitu perjalanan wisata yang membahas tentang masak- memasak. Berbeda dengan produk wisata lainnya seperti wisata bahari dan wisata budaya ataupun alam yang biasanya dipasarkan sebagai produk wisata utama, wisata kuliner biasanya dipasarkan sebagai produk wisata penunjang.

Panganan khas daerah merupakan makanan yang biasa dikonsumsi di suatu daerah. Berbagai karakter panganan pada daerah-daerah biasanya mencerminkan karakter masyarakatnya, sebagai contoh pada daerah pegunungan, dikarenakan iklim didaerah pegunungan yang relatif dingin, maka umumnya olahan panganannya berbahan dasar sayur dan disajikan dalam suhu yang panas dan sedikit rasa yang pedas, ini bertujuan agar badan tetap hangat, berbeda halnya pada daerah pantai, maka olahan panganan yang disajikan masyarakatnya banyak menggunakan olahan hasil laut.

\subsection{UML (Unified Modeling Language)}

UML merupakan singkatan dari Unified Modeling Language adalah sekumpulan alat yang digunakan untuk melakukan abstraksi terhadap sebuah sistem atau perangkat lunak berbasis objek. UML juga menjadi salah satu cara untuk mempermudah pengembangan aplikasi yang berkelanjutan dan juga dapat menjadi alat bantu untuk transfer ilmu tentang sistem atau aplikasi yang akan dikembangkan dari satu developer ke developer lainya. UML diaplikasikan untuk maksud tertentu, biasanya antara lain untuk, merancang perangkat lunak, Sarana komunikasi antara perangkat lunak dengan proses sistem, menjabarkan sistem secara rinci untuk analisa dan mencari apa yang diperlukan sistem.

\subsection{Web server}

Web Server adalah sebuah perangkat lunak yang berfungsi untuk menerima dan melayani permintaan yang dikirimkan user melalui browser kemudian ditampilkan kepada user sesuai dengan permintaan yang dikirimkan ke server. Webserver saat ini bekerja sebagai penyedia layanan yang dapat diakses banyak pengguna, adapun fungsi utama Webserver yaitu agar dapat melakukan atau mentransfer berkas-berkas permintaan dari pengguna melalui protocol-protokol komunikasi yang ditentukan. Halaman web yang diminta yaitu berkas yang berupa teks, video-video, gambargambar, file dan masih banyak lagi. pemanfaatan webserver juga berfungsi untuk melakukan atau mengirim semua aspek pemberkasan dalam sebuah halaman website berupa teks, video, gambar dan banyak lagi. Salah satu contoh dari Web Server adalah Apache. Apache merupakan web server yang paling banyak dipergunakan di Internet.

\section{Metode Dan Pembahasan}

\subsection{Analisis Sistem}

Analisis Sistem yang dirancang adalah sistem Informasi wisata kuliner berbasis web di Kabupaten Majene. Sistem informasi ini sangat bermanfaat untuk memberi bantuan kepada para wisatawan baik itu masyarakat sekitar Kabupaten Majene maupun masyarakat lokal dalam memperoleh Informasi terkait panganan Khas Mandar. Website wisata kuliner ini memberikan Informasi tentang berbagai macam panganan khas Mandar, baik berupa panganan yang sudah dikemas maupun tidak dan makanan berat yang menonjolkan ciri dan cita rasa panganan khas suku Mandar, website ini juga meberikan informasi terkait lokasi-lokasi wisata kuliner yang menyedia olahan panganan tersebut sehingga sangat membantu para wisatawan maupun masyarakat lokal untuk mencari dan ingin mencicipi pangananpanganan khas suku Mandar tersebut.

\subsection{Perancangan Sistem}

Perancangan Sistem bertujuan untuk memberikan gambaran umum antarmuka tentang sistem informasi yang telah dirancang dan dibangun agar pengguna dapat memahami penggunaan sistem informasi untuk mencari informasi terkait wisata kuliner dan panganan khas Mandar di Kabupaten Majene.

Perancangan sistem yang dilakukan yaitu membahas beberapa model sistem yang menggunakan Model Unified Modeling Language (UML). Model Unified Modeling Language (UML) yang digunakan adalah use case diagram dan activity diagram

\subsection{Use case Diagram}

Use Case Diagram mempunyai fungsi yang berrtujuan untuk memberi penggambaran secara grafis tentang perilaku sistem serta memberi penggambaran tentang fungsionalitas yang 
diinginkan dari sistem informasi kuliner berbasis website ini.

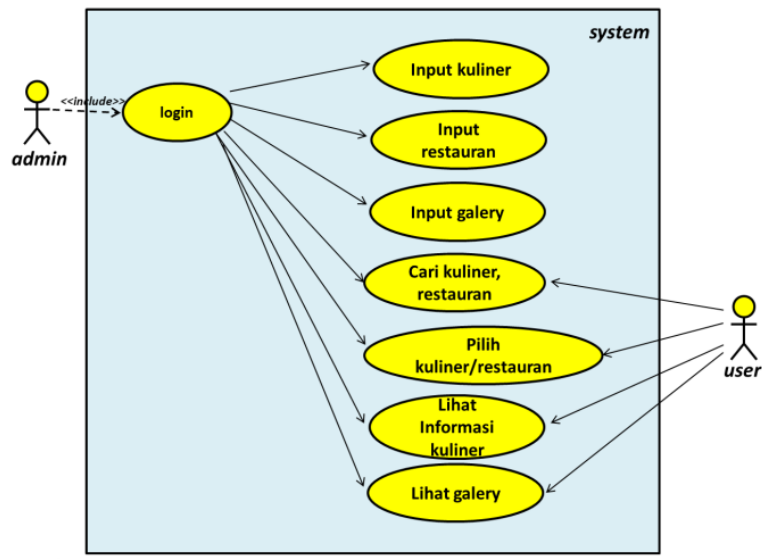

Gambar 1 Use Case Diagram

Terlihat pada Gambar use case diagram di atas yaitu Gambar 1 dapat diamati bahwa dalam pengoperasian sistem ada dua aktor dan beberapa proses-proses sistem berbasis website ini yang dapat digunakan oleh kedua aktor tersebut, di mana Setiap proses yang ditangani aktor dapat dilihat pada penjelasan berikut ini:

1) Admin

Sebelum mengoperasikan setiap proses yang ada pada dashboard, setiap admin sebelumnya pada saat pertama kali mengakses terlebih dahulu harus melakukan login.

Setelah login maka admin mempunyai akses penuh terhadap sistem, adapun beberapa proses yang dapat ditangani oleh admin meliputi input kuliner, input restoran, input gallery

2) User

Sebagai seorang pengguna atau user, adapun akses yang dapat dilakukan oleh pengguna adalah pengguna dapat mencari wisata kuliner dan restoran serta memilih kuliner/restoran, dapat melihat informasi kuliner/restoran dan juga dapat melakukan pencarian destinasi wisata melalui dokumentasi yang terdapat pada gallery.

\subsection{Diagram Aktivitas (Activity Diagram)}

Activity diagram akan digunakan sebagai model aktivitas alur kerja sistem, alur sistem yang digunakan atau dimodelkan dalam activity diagram ini terfokus pada banyaknya aktivitas yang terkait dan terjadi dalam suatu proses tunggal. Dengan kata lain, diagram ini memberikan petunjuk tentang banyaknya aktifitas yang terjadi pada sistem informasi website tersebut yang sangat bergantung dengan satu dan lainnya.

Activity diagram pada sistem informasi berbasis website untuk pencarian informasi wisata kuliner dan panganan khas Mandar di kabupaten Majene yang telah dibangun digambarkan sebagai berikut :

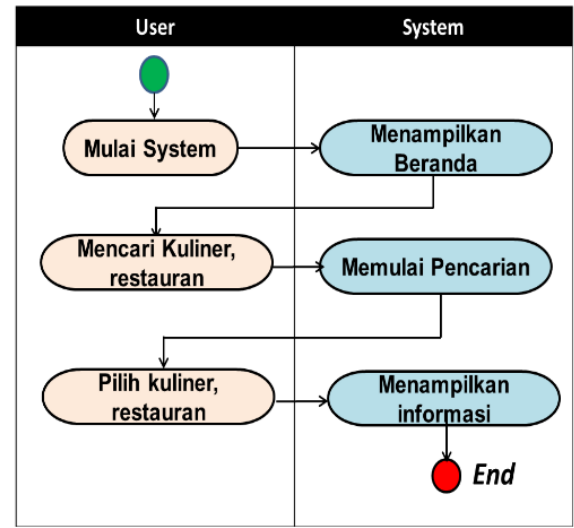

Gambar 2 Diagram Aktivitas

\subsection{Relasi Antartabel}

Relasi antartabel penggunaan database yang telah dibangun dapat dilihat pada Gambar 3

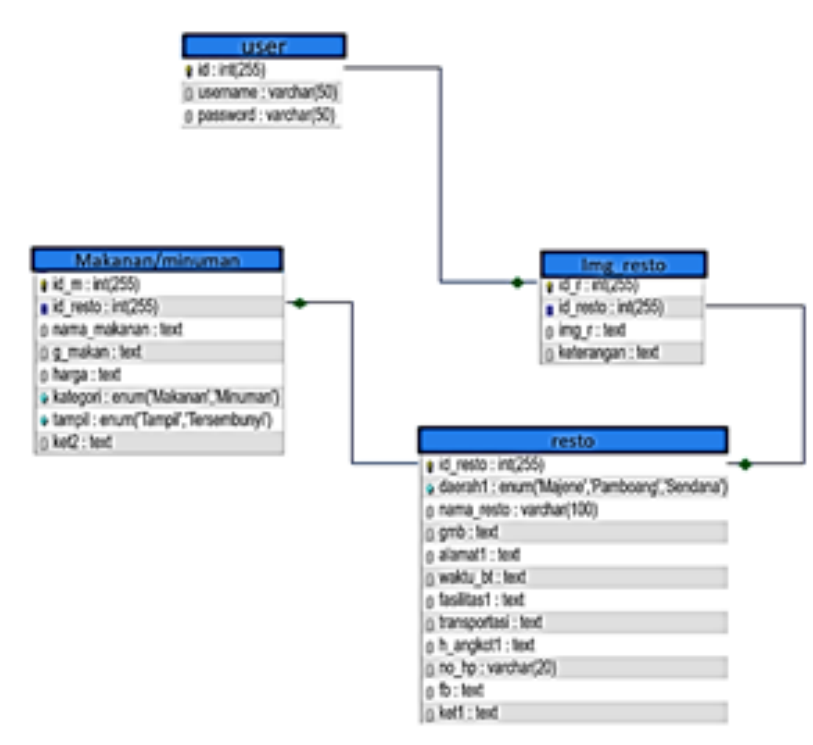

Gambar 3 Relasi Antartabel

Rancangan database sistem informasi website kuliner ini terdiri dari 4 tabel, yaitu resto.tbl, user.tbl, imgresto.tbl, makanan/minuman.

Rancangan database sistem informasi website kuliner ini menggunakan database MySQL phpMyAdmin sebagai localhost database. 


\section{Hasil dan Implementasi}

Implementasi antarmuka pengguna merupakan suatu cara atau langkah yang digunakan untuk memperkenalkan dan memperlihatkan bagaimana cara pengguna mengoperasikan website yang akan dirancang.

Pada bagian ini akan ditampilkan hasil akhir dari sistem dan antarmuka sistem yang sudah dibangun serta menjelaskan bagaimana cara mengoperasikannya. Pada media informasi website wisata kuliner panganan khas Mandar di Kabupaten Majene yang dibangun ini, terdapat dua hak akses yang menggunakan sistem yaitu user dan administrator (masyarakat lokal, pendatang/wisatawan). Setiap halaman dijabarkan pada subbab berikutnya.

\subsection{Halaman Login}

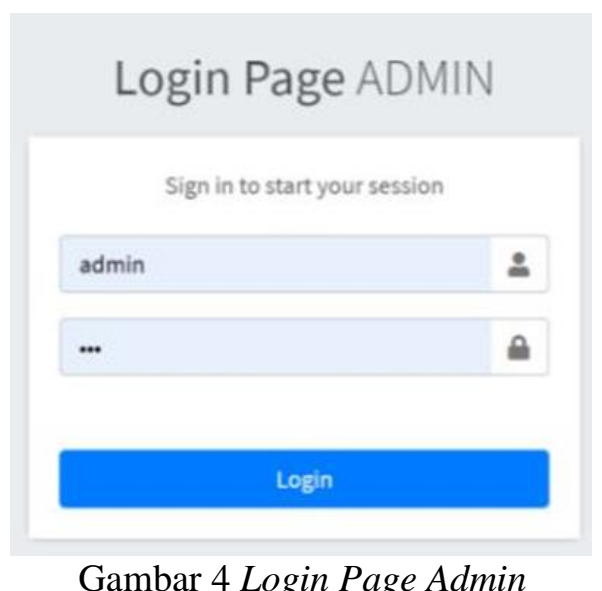

Login Page Admin Menampilkan tampilan login, untuk login diharuskan memasukkan username dan password yang tepat, memasukkan username atau password yang tidak tepat, direspon dengan pemberitahuan username atau password salah.

Apabila username dan password benar, maka akan langsung masuk ke dashboard admin, di mana admin dapat mengelola data wisata kuliner.

\subsection{Halaman Dashboard}

Halaman dashboard admin, merupakan antarmuka yang dibangun untuk admin untuk mendapatkan akses penuh terhadap sistem informasi berbasis website yang telah dibangun, di halaman dashboard ini admin dapat mengelola semua bagian-bagian dari sistem yang dibutuhkan oleh masyarakat terkait wisata kuliner dan panganan khas Mandar yang ada di kabupaten Majene.

\subsection{Kelola Restoran}

Adapun hal yang paling utama yang dikelola oleh admin adalah, kelola restoran, dan kelola makanan dan minuman, yang disajikan pada gambar di bawah ini:

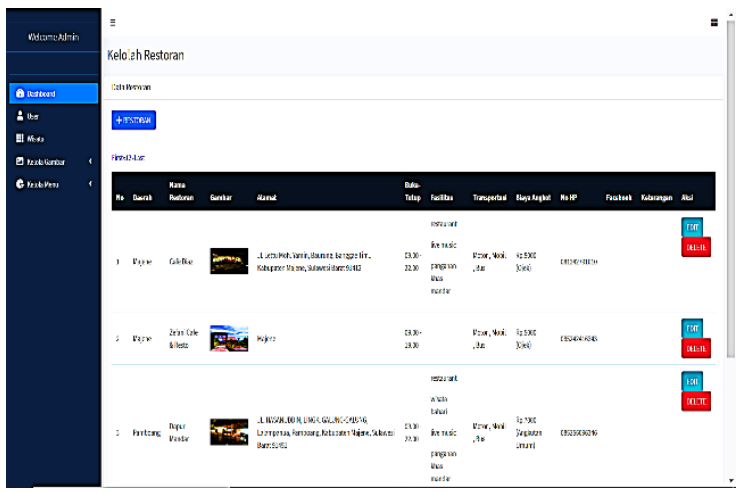

Gambar 5 Halaman Kelola Restoran

Halaman ini merupakan halaman dashboard admin, di mana pada halaman ini admin dapat memasukkan atau mengelola berbagai macam jenis restoran yang ada di Kabupaten Majene terkait kuliner panganan khas Mandar.

Pada halaman ini admin akan memasukkan secara detail terkait restoran seperti nama restoran, alamat, gambar, transportasi, dan info-info terkait lainnya

\subsection{Kelola Makanan dan Minuman}

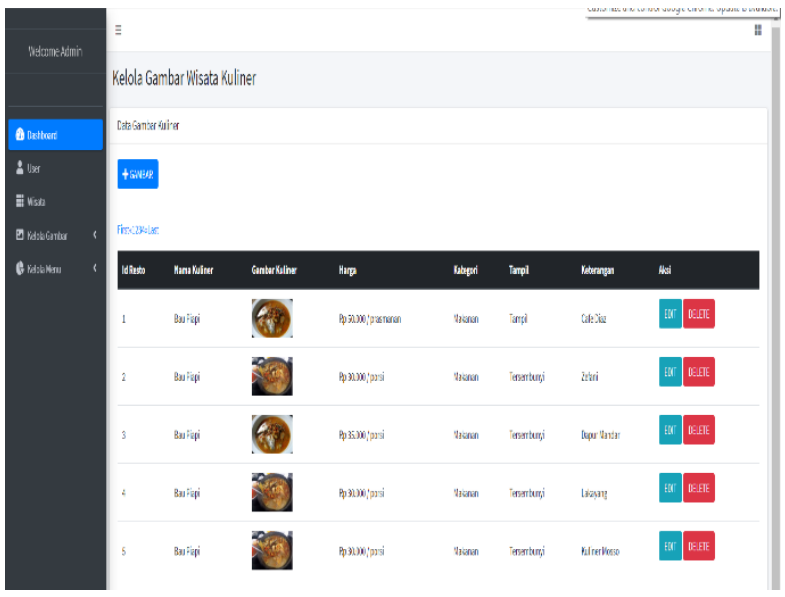

Gambar 6 Halaman Kelola Makanan \& Minuman

Halaman ini merupakan halaman dashboard admin, di mana pada halaman ini admin dapat memasukkan atau mengelola berbagai 
macam makanan dan minuman panganan khas Mandar yang ada di Kabupaten Majene.

Pada halaman ini admin akan memasukkan secara detail terkait makanan dan minuman panganan khas Mandar yang ada di Kabupaten Majene seperti nama makanan dan minuman, harga makanan dan info-info terkait lainnya.

\subsection{Halaman Utama untuk Pengguna}

Halaman ini merupakan halaman utama bagi pengunjung yang dapat diakses oleh siapa saja yang akan membuka website tersebut tanpa harus melakukan login atau registrasi terlebih dahulu.

Halaman ini berisi menu-menu yang berkaitan dengan informasi kuliner panganan khas Mandar yang terdiri dari menu kuliner, galery dan kontak. Tampilan halaman utama seperti terlihat pada gambar 7 .

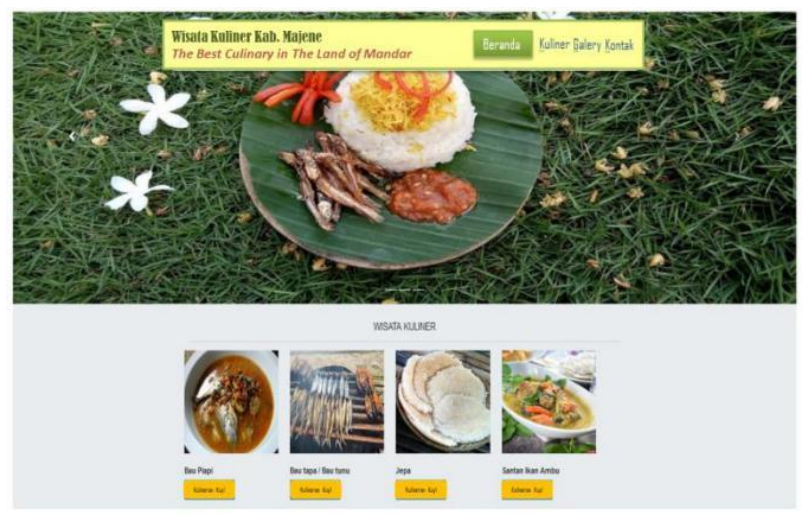

\section{Gambar 7 Halaman Utama User}

\subsection{Menu Kuliner}

Halaman ini merupakan halaman pada menu kuliner, di mana pada halaman ini terdapat dua sub menu yaitu restoran dan kuliner panganan khas Mandar di Kabupaten Majene yang ketika di klik maka akan langsung masuk ke menu restoran ataupun kuliner secara mendetail.

\subsection{Restoran}

Dengan memilih menu restoran pengunjung dapat melihat berbagai info detail terkait restoran seperti, alamat, jam buka-tutup, fasilitas, trasnportasi yang dapat digunakan, biaya trasnportasi, contact person, dan juga menu-menu apa saja yang tersedia di restoran tersebut. Tampilan dapat dilihat pada gambar 8 .

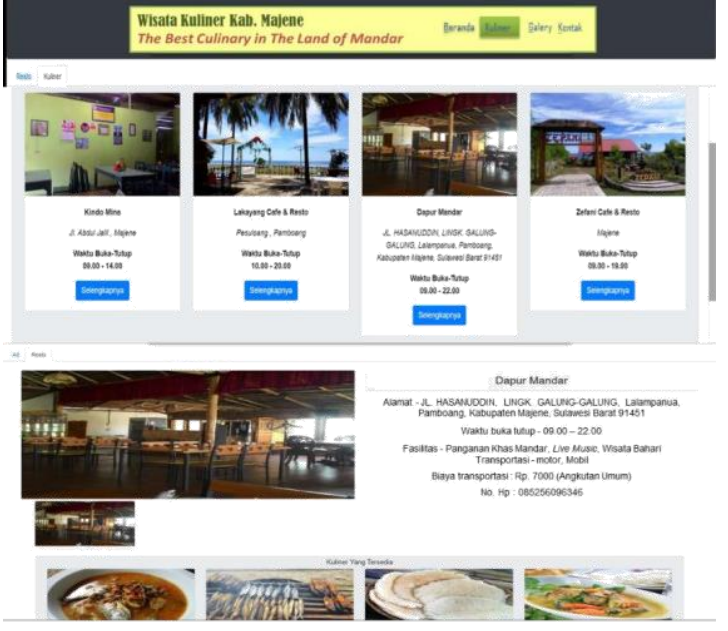

Gambar 8 Halaman Restoran

\subsection{Kuliner}

Dengan memilih menu kuliner pengunjung dapat melihat berbagai jenis penganan khas Mandar, info detail terkait lokasi yang menyediakan panganan tersebut akan muncul ketika pengguna memilih salah satu gambar yang diinginkan. Tampilan dapat dilihat pada Gambar 9.

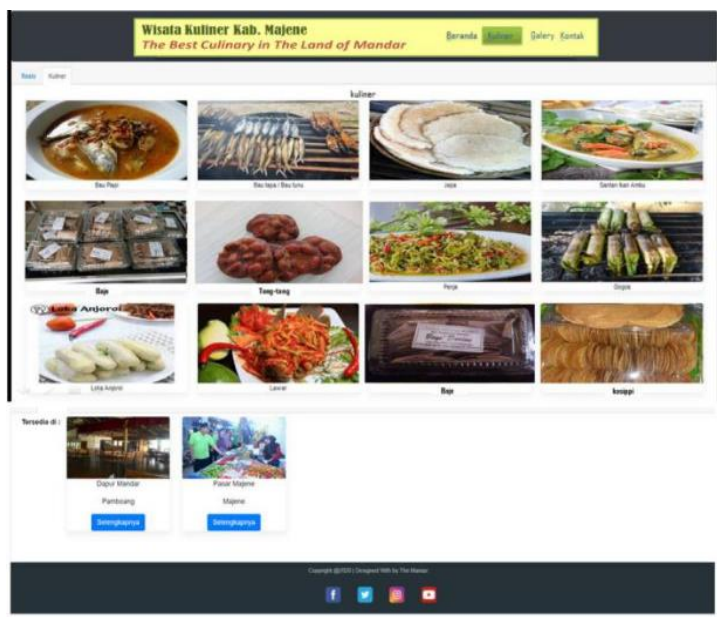

Gambar 9 Halaman Kuliner

\subsection{Pengujian Sistem}

Tujuan dilakukannya pengujian adalah untuk mengetahui tingkat keberhasilan sistem apakah sistem yang dibangun sudah sesuai dengan yang dibutuhkan. Tahapan pengujian sistem ini dilakukan menggunakan pengujian quisioner dan black box. Quisioner yang telah diujikan terhadap 15 orang responden yang semuanya terdiri dari masyarakat umum. 


\subsection{Pengujian Blackbox}

Hasil uji black box testing dapat dilihat dari pada table 1 di bawah ini:

Tabel 1 Hasil Pengujian Black Box

\begin{tabular}{|c|c|c|c|c|}
\hline No & Kasus uji & Scenario uji & Hasil yang diharapkan & $\begin{array}{c}\text { Hasil } \\
\text { pengujian }\end{array}$ \\
\hline 1 & $\begin{array}{l}\text { TAMPILAN } \\
\text { AWAL }\end{array}$ & $\begin{array}{l}\text { Memilih laumcher icon aplikasi } \\
\text { wisata kuliner kabupaten Majene }\end{array}$ & $\begin{array}{l}\text { Ketika launcher icon maka } \\
\text { aplikasi akan berjalan dan } \\
\text { masuk ketampilan awal }\end{array}$ & Berhasil \\
\hline 2 & $\begin{array}{l}\text { MENU } \\
\text { INFORMASI } \\
\text { WISATA } \\
\text { KULINER }\end{array}$ & $\begin{array}{l}\text { Akan menampilkan } \\
\text { pilihan menu yaitu } \\
\text { 1. Restaurant } \\
\text { 2. } \text { kuliner }\end{array}$ & $\begin{array}{l}\text { Ketika memilih menu wisata } \\
\text { Akan menampilkan } 4 \text { pilihan } \\
\text { menu yaitu } \\
\text { 1. Restaurant akan } \\
\text { menampilkan berbagai } \\
\text { macam restaurant yang } \\
\text { menjual panganan khas } \\
\text { Mandar di Kabupaten } \\
\text { Majene } \\
\text { 2. Kuliner akan menampillkan } \\
\text { berbagai macam Jenis } \\
\text { Kuliner yang menjual } \\
\text { panganan khas Mandar di } \\
\text { Kabupaten Majene }\end{array}$ & Berhasil \\
\hline 4 & GALLERY & $\begin{array}{l}\text { akan menampillkan dokumentasi } \\
\text { berbagai macam restaurant dan } \\
\text { jenis panganan khas Mandar } \\
\text { yang dapat dijadikan sebagai } \\
\text { rekomendasi bagipara } \\
\text { wisatawan }\end{array}$ & $\begin{array}{l}\text { Ketika memilih menu gallery } \\
\text { akan menampilkan } \\
\text { dokumentasi berbagai macam } \\
\text { jenis panganan khas Mandar }\end{array}$ & Berhasil \\
\hline
\end{tabular}

Pengujian blackbox sistem ini digunakan untuk menguji apakah sistem telah berjalan sesuai dengan fungsinya atau tidak dan apakah sistem sudah bebas dari kesalahan atau error.

\subsection{Pengujian Quisioner}

Pengujian yang dilakukan terhadap 15 responden ini terdiri dari pengguna umum atau masyarakat umum yang fungsinya untuk mengetahui tingkat kepuasan dari para pengguna sistem. sebelum mengisi quisioner, sebelumnya responden dapat melihat serta mengoperasikan sistem yang telah dibangun, selanjutnya responden diminta menjawab pertanyaan yang terdapat pada form quisioner yang disediakan. Adapun hasil pengujiannya dapat dilihat pada Tabel 2 dan Tabel 3.

Dari tabel hasil quisioner yang dinilai oleh 15 responden yang telah menjawab pertanyaan di atas penulis menyimpulkan bahwa persentase tertinggi berada pada pertanyaan nomor $6,7,8$ sebesar $88 \%$ yaitu sangat setuju berkaitan proses akses website, penggunaan dan fungsi-fungsi utama lainnya yaitu memberikan kemudahan bagi masyarakat karena tampilannya yang sederhana dan mudah untuk dipahami dalam mencari informasi mengenai kuliner panganan khas Mandar di Kabupaten Majene. Persentase yang paling rendah berada pada pertanyaan nomor 3 yaitu sebesar $76 \%$ yaitu tidak semua orang yang dapat dengan mudah mengakses website tersebut, namun ini bukan masalah yang besar dikarenakan persentasenya masih bisa memenuhi kebutuhan pengguna.

Tabel 2 Hasil Quisioner

\begin{tabular}{|c|l|c|c|c|c|c|}
\hline \multirow{2}{*}{ No } & \multicolumn{3}{|c|}{ Pertanyaan } & \multicolumn{5}{|c|}{ Jawaban } \\
\cline { 2 - 8 } & \multicolumn{1}{|c|}{ SS } & S & KS & TS & STS \\
\hline 1. & Tampilan halaman utama system & 4 & 11 & - & - & - \\
\hline 2. & Tampilan semua menu pada system & 5 & 10 & - & - & - \\
\hline 3. & $\begin{array}{l}\text { Media informasi Website mudah untuk } \\
\text { diakses oleh semua orang }\end{array}$ & 6 & 7 & - & - & - \\
\hline 4. & $\begin{array}{l}\text { Media informasi Website memberikan } \\
\text { kemudahan dalam mencari informasi } \\
\text { panganan khas mandar }\end{array}$ & 5 & 10 & - & - & - \\
\hline 5. & $\begin{array}{l}\text { Media informasi website ini meyediakan } \\
\text { informasi yang jelas }\end{array}$ & 5 & 10 & - & - & - \\
\hline 6. & $\begin{array}{l}\text { Proses mengakses pada media informasi } \\
\text { website ini cukup mudah dan Jelas }\end{array}$ & 6 & 9 & - & - & - \\
\hline 7. & $\begin{array}{l}\text { Tampilan website ini sederhana dan mudah } \\
\text { dipahami }\end{array}$ & 6 & 9 & - & - & - \\
\hline 8. & $\begin{array}{l}\text { Menurut anda, apakah mendia informasi } \\
\text { website wisata kuliner panganan khas } \\
\text { mandar ini layak untuk di publikasikan di } \\
\text { masyarakat }\end{array}$ & 6 & 9 & - & - & - \\
\hline
\end{tabular}

Tabel 3 Analisa Hasil Uji Quisioner

\begin{tabular}{|c|c|c|c|c|c|c|c|}
\hline \multirow[t]{2}{*}{$\mathrm{N}_{0}$} & \multirow[t]{2}{*}{ Pertanyaan } & \multicolumn{5}{|c|}{ JAIVABAN } & \multirow[t]{2}{*}{ Persentase } \\
\hline & & $\mathrm{SS}(5)$ & $S(4)$ & $\mathrm{KS}(3)$ & $\operatorname{TS}(2)$ & STS(1) & \\
\hline 1 & $\mathrm{Pl}$ & 4 & 11 & 0 & 0 & 0 & $85,2 \%$ \\
\hline 2 & P2 & 5 & 10 & 0 & 0 & 0 & $86 \%$ \\
\hline 3 & P3 & 6 & 7 & 0 & 0 & 0 & $76 \%$ \\
\hline 4 & P4 & 5 & 10 & 0 & 0 & 0 & $86 \%$ \\
\hline 5 & P5 & 5 & 10 & 0 & 0 & 0 & $86 \%$ \\
\hline 6 & $\mathrm{P} 6$ & 6 & 9 & 0 & 0 & 0 & $88 \%$ \\
\hline 7 & P7 & 6 & 9 & 0 & 0 & 0 & $88 \%$ \\
\hline 8 & P8 & 6 & 9 & 0 & 0 & 0 & $88 \%$ \\
\hline
\end{tabular}

\section{Kesimpulan} adalah:

Adapun kesimpulan dari penelitian ini

1. Perancangan media informasi website wisata kuliner ini mampu memberikan informasi kepada wisatawan dan masyarakat lokal serta dapat menjadi sarana promosi bagi pemilik rumah makan panganan khas Mandar agar dapat diketahui para wisatawan maupun masyarakat lokal sehingga pemasarannya terjangkau dan lebih merata.

2. Perancangan media informasi sudah menggunakan desain yang bagus dan interface yang mudah unutk digunakan oleh user, serta memberikan tampilan yang menarik dan mudah dimengerti, sehingga pengunjung mendapatkan kepuasan pada saat menggunkan media informasi website kuliner panganan khas Mandar di Kabupaten Majene ini. 


\section{Saran}

Dengan memperhatikan dari kesimpulan di atas penulis menyarankan beberapa hal di antaranya:

1) Tampilan Interface media informasi website ini masih bisa dikembangkan dan ditambahkan menu-menu lain yang sesuai dengan kebutuhan pengguna.

2) Media Informasi panganan khas Mandar di kabupaten Majene ini dibangun berbasis Website sehingga pengembang lainnya masih dapat membuat tampilann yang lebih menarik dan mengembangkannya menjadi sebuah media berbasis android

\section{Daftar Pustaka}

Eni Farida, S. S. (2018). Sistem Informasi Wisata Kuliner Berbasis Web Sebagai Media Promosi Kuliner di Kota Malang. Jurnal Teknologi Informasi, 9(1).

Erta Kartini, P. S. (2017). Sistem Informasi Wisata Kuliner di Kota Medan Berbasis Web. MEANS (Media Informasi Analisa Dan Sistem), 2(2).

Fathansyah. (2015). Basis Data (2nd ed.). Bandung: Informatika (71-78)

Hakim, L. (2010). Bikin Website Super Keren Dengan PHP dan Jquery. Yogyakarta: Lokomedia (12$30)$.

Irpan Ahmad Fauzi, A. M. (2017). Perancangan Sistem
Informasi Kuliner Di Brother Caffe Berbasis Web. Jurnal Algoritma Sekolah Tinggi Teknologi Garut, 14(2).

Khairus Suhada, Danuri, F. P. P. (2017). Aplikasi web promosi kuliner dan rumah makan online. Jurnal Teknologi Informasi \& Komunikasi Digital Zone, $8(1)$.

Kristanto, A. (2018). Perancangan Sistem Informasi dan Aplikasinya. Yogyakarta: Gava Media (23-40).

Lucky. (2008). XML Web Service Aplikasi Desktop, Interest dan Handphone. Depok: Jasakom (51-64).

Nugroho, B. (2013). Dasar Pemrograman Web PHP $M y S Q L$ dengan Dreamweaver. Yogyakarta: Gava Media (1-9)

Priyanto Hidayatullah, J. K. K. (2016). Pemograman $W E B$. Bandung: Informatika.

Rosa A.S, M. S. (2016). Rekayasa Perangkat Lunak (4th ed.). Bandung: Informatika (133-155)

Suryaningrat, G. N. J. (2016). Perancangan Sistem Informasi Wisata Kuliner Berbasis Web Dengan Menggunakan Ajax dan Code Igniter. Jurnal Sistem Dan Informatika, 10(2).

Syahid, H. N. (2016). Rancang Bangun Sistem Informasi Wisata Kuliner Di Kota Klaten Berbasis Web. Universitas Muhammadiyah Surakarta. Retrieved from http://eprints.ums.ac.id/45034/1/Naskah Publikasi.pdf

Simamarta, J. (2010). Rekayasa Web. Medan: Andi Yogyakarta (47-61) 